\title{
Orthostatic Intolerance and Postural Orthostatic Tachycardia Syndrome in Joint Hypermobility Syndrome/Ehlers-Danlos Syndrome, Hypermobility Type: Neurovegetative Dysregulation or Autonomic Failure?
}

\author{
Claudia Celletti, ${ }^{1}$ Filippo Camerota, ${ }^{1}$ Marco Castori, ${ }^{2}$ Federica Censi, ${ }^{3}$ \\ Laura Gioffrè, ${ }^{4}$ Giovanni Calcagnini, ${ }^{3}$ and Stefano Strano ${ }^{4}$ \\ ${ }^{1}$ Physical Medicine and Rehabilitation, Umberto I Hospital, Rome, Italy \\ ${ }^{2}$ Unit of Clinical Genetics, San Camillo-Forlanini Hospital, Rome, Italy \\ ${ }^{3}$ Department of Cardiovascular, Dysmetabolic and Aging-Associated Diseases, Italian Institute of Health, Rome, Italy \\ ${ }^{4}$ Department of Heart and Great Vessels "A. Reale", Sapienza University of Rome, Rome, Italy \\ Correspondence should be addressed to Claudia Celletti; clacelletti@gmail.com
}

Received 31 October 2016; Revised 16 January 2017; Accepted 19 January 2017; Published 12 February 2017

Academic Editor: Ramazan Akdemir

Copyright (C) 2017 Claudia Celletti et al. This is an open access article distributed under the Creative Commons Attribution License, which permits unrestricted use, distribution, and reproduction in any medium, provided the original work is properly cited.

\begin{abstract}
Background. Joint hypermobility syndrome/Ehlers-Danlos syndrome, hypermobility type (JHS/EDS-HT), is a hereditary connective tissue disorder mainly characterized by generalized joint hypermobility, skin texture abnormalities, and visceral and vascular dysfunctions, also comprising symptoms of autonomic dysfunction. This study aims to further evaluate cardiovascular autonomic involvement in JHS/EDS-HT by a battery of functional tests. Methods. The response to cardiovascular reflex tests comprising deep breathing, Valsalva maneuver, 30/15 ratio, handgrip test, and head-up tilt test was studied in 35 JHS/EDS-HT adults. Heart rate and blood pressure variability was also investigated by spectral analysis in comparison to age and sex healthy matched group. Results. Valsalva ratio was normal in all patients, but $37.2 \%$ of them were not able to finish the test. At tilt, $48.6 \%$ patients showed postural orthostatic tachycardia, $31.4 \%$ orthostatic intolerance, $20 \%$ normal results. Only one patient had orthostatic hypotension. Spectral analysis showed significant higher baroreflex sensitivity values at rest compared to controls. Conclusions. This study confirms the abnormal cardiovascular autonomic profile in adults with JHS/EDS-HT and found the higher baroreflex sensitivity as a potential disease marker and clue for future research.
\end{abstract}

\section{Introduction}

Ehlers-Danlos syndrome (EDS) is an umbrella term for a group of heritable soft connective tissue disorders mainly characterized by generalized joint hypermobility, skin texture abnormalities, and visceral and vascular fragility or dysfunctions [1]. Current nosology identifies six major EDS variants, with the classical, hypermobility, and vascular types being the most common [1]. More recently, different studies suggested and partly demonstrated a clinical overlap between EDS, hypermobility type (EDS-HT), and the joint hypermobility syndrome (JHS) $[2,3]$. JHS is to date defined as an underdiagnosed rheumatologic condition showing generalized joint hypermobility, chronic musculoskeletal pain, and additional findings and presenting a common familial aggregation [4]. The diagnosis of EDS is confirmed by molecular tools in most types except for EDS-HT and the cognate JHS, both remaining clinical diagnoses based on available criteria $[4,5]$. At the moment, the prevalent opinion is to provisionally consider JHS and EDS-HT a single entity (i.e., JHS/EDSHT) [2]. In JHS/EDS-HT, generalized joint hypermobility with recurrent joint dislocations and chronic moderate to severe pain were the most frequent and severe complaints, but also muscle cramps, tendinitis, headache, and fatigue are frequently reported [6]. Impaired proprioception, postural control, and muscular strength are factors that may contribute to joint instability [7]. The clinical spectrum associated with JHS/EDS-HT is not limited to the musculoskeletal 
apparatus. Among the common visceral manifestations of JHS/EDS-HT, symptoms possibly linked to an underlying autonomic dysfunction were repeatedly reported $[8,9]$. In particular, different authors described orthostatic intolerance (OI) and postural orthostatic tachycardia symptoms (POTS) in JHS/EDS-HT [10-13].

POTS is one of the most common manifestations of $\mathrm{OI}$ and is defined as a sustained heart rate (HR) increase of $\geq 30 \mathrm{bpm}$ or increase of $\mathrm{HR}$ to $\geq 120 \mathrm{bpm}$ usually within the first 10 minutes of orthostasis associated with symptoms of OI but without orthostatic hypotension $(\mathrm{OH})$, which is in turn defined as a drop of $>20 \mathrm{mmHg}$ in systolic blood pressure (BP) or $>10 \mathrm{mmHg}$ in diastolic BP independently of changes in HR $[14,15]$. The diagnosis of POTS is instrumental and the association with symptoms is not linear. Therefore, there are patients manifesting complaints likely related to some autonomic dysfunction but not meeting the diagnostic criteria of POTS. The term OI is used to describe patients developing symptoms on standing or head-up tilt (HUT) but not fulfilling the criteria of POTS [16].

This study aims to evaluate the autonomic response profile and related symptoms in JHS/EDS-HT by HUTtest and spectral analysis of heart rate and blood pressure variability.

\section{Materials and Methods}

2.1. Subjects. Patients were selected from those attending the Joint Hypermobility Outpatient Service at the Umberto I University Hospital in Rome. The diagnosis of JHS and EDS-HT was established by applying published diagnostic criteria. In particular, generalized joint hypermobility was assessed by the Beighton score (BS) with a maximum score of nine and a cut-off of four $(\geq 4 / 9)$ for JHS and five $(\geq 5 / 9)$ for EDS-HT [17]. Then, Villefranche criteria were used for EDS-HT [1], whereas Brighton score was applied for JHS [4]. Although a consensus is still lacking on the correct procedure of performing a satisfactory differential diagnosis, partially overlapping disorders were excluded on clinical and, if needed, molecular grounds as detailed elsewhere [18]. None of the patients had diabetes, heart failure, severe arterial hypertension, or cardiac arrhythmias, nor had any medications that might influence autonomic cardiovascular regulation. All the participants gave their informed consent before enrolment.

2.2. Procedure. All patients were studied at the Autonomic Cardiovascular Laboratory and Syncope Unit of the Department of Heart and Great Vessels "A. Reale", Umberto I University Hospital in Rome. To exclude potentially preexisting cardiovascular disease not linked to the underlying genetic disorder, all patients underwent a full cardiovascular evaluation comprising complete history and physical examination, 12-lead electrocardiogram (ECG), $24 \mathrm{H}$ Holter, hematocrit, and echocardiogram. Selected patients underwent cardiovascular reflex tests comprising deep breathing, Valsalva maneuver, 30/15 ratio, handgrip test, and HUT.

During the tests, continuous arterial BP was noninvasively recorded using a photo-plethysmographic technique
(CNSystems Task-Force Monitor 3040i). The HR and BP beat-to-beat variability series were calculated according to the HR variability (HRV) guidelines [19]. Each beat was obtained by numerical recognition of $R$ waves ( $R-R$, tachogram). The systolic values were detected in the same cardiac cycle (S-S, systogram).

\subsection{Cardiovascular Reflex Tests}

2.3.1. Deep Breathing. Participants breathed maximally at a frequency of 6 breaths per minute, following the lead of an oscillating ball on a computer screen. A total of 8 breathing cycles were recorded and the test was repeated after 2 min of rest. The deep breathing test was considered normal if heart rate variation was 15 beats/min or more, borderline if 11-14 beats/min, and pathological if 10 beats/min or less [20]. The HR range was calculated as a measure of parasympathetic reactivity [21].

2.3.2. Valsalva Maneuver. Participant blew into a mouthpiece between 40 and $50 \mathrm{mmHg}$ for $15 \mathrm{sec}$ [21]. The maneuver was repeated 3 times or until at least 2 reproducible BP recordings were obtained. Faulty trials (inadequate pressure or duration) were excluded. In between trials, $3 \mathrm{~min}$ of rest was provided to stabilize HR and BP. The best-performed maneuver was selected for evaluation. The Valsalva ratio (VR) was calculated (parasympathetic measure), and the 4 phases in the BP response were quantified (sympathetic reactivity) [21]. Respect to baseline, the maximal drop of systolic and diastolic BP (SBP and DBP) at phase II early (IIE), SBP and $\mathrm{DBP}$ at phase II late (IIL), and overshoot at phase IV during Valsalva maneuver were computed. Difference between SBP and DBP from phase IIE to phase IIL and overshoot at phase IV during the maneuver were considered indexes of sympathetic vascular peripheral response.

\subsubsection{Early Heart Rate Response to Standing Up (30-15 Ratio).} Subjects were asked to stand at rest in the supine position for $5 \mathrm{~min}$ and then to assume the standing position without help as quickly as possible according to his/her physical abilities. The cardiac chronotropic response characteristic is expressed by the ratio $30: 15$, that is, the ratio between the longest R-R interval after the maneuver (around the thirtieth beat) and the shortest R-R interval around the fifteenth beat. Results were evaluated considering as normal a ratio $\geq 1.04$, as borderline when the ratio value was between 1.01 and 1.03, and as pathological when the value is $\leq 1.00$ [20].

2.3.4. BP Response to Sustained Handgrip. Handgrip was maintained at 30 percent of maximal voluntary contraction until the maximum time of 5 minutes, using a dynamometer. Pressure was measured every minute until the end of the test. Magnitude of the response was given by the difference between the diastolic BP measured just before the release of the dynamometer and that measured before the test. Handgrip test was considered successfully performed if patients were able to maintain a constant effort for at least 1 minute. 
TABLE 1: Response to cardiovascular reflex tests.

\begin{tabular}{lcccc}
\hline Test & $\begin{array}{c}\text { Normal } \\
\text { number }(\%)\end{array}$ & $\begin{array}{c}\text { Borderline } \\
\text { number }(\%)\end{array}$ & $\begin{array}{c}\text { Pathological } \\
\text { number }(\%)\end{array}$ & $\begin{array}{c}\text { Not evaluable } \\
\text { number }(\%)\end{array}$ \\
\hline Deep breathing & $35 / 35(100)$ & - & - & - \\
Valsalva ratio & $19 / 35(54.3)$ & $3 / 35(8.5)$ & - & $13 / 35(31.4)$ \\
30/15 ratio & $17 / 35(48.57)$ & $18 / 35(51.4)$ & - & $35 / 35(100)$ \\
Sustained handgrip & - & - & - \\
\hline
\end{tabular}

2.3.5. HUT. Participants rested quietly for 5 minutes. Baseline HR and BP were calculated as the mean from 40 seconds to 10 seconds before tilting. Then, the table was slowly tilted upright to an angle of $70^{\circ}$ for a maximum of 20 minutes. Patients were asked to report all symptoms and the test was aborted when either orthostatic symptoms or pain became intolerable. $\mathrm{OH}$ was defined as a sustained diastolic BP drop of at least $10 \mathrm{mmHg}$ or a systolic BP drop of at least $20 \mathrm{mmHg}$ for normotensive subjects [22]. Vasovagal syncope was defined as a sudden BP and HR decline coupled with loss of consciousness. POTS was defined as a sustained HR rise of at least $30 \mathrm{bpm}$ or a HR of at least $120 \mathrm{bpm}$ in the first $10 \mathrm{~min}$ of tilt, without concomitant $\mathrm{OH}$ [23]. OI was the term used to define symptoms at HUT in the absence of the abovementioned criteria.

2.3.6. Spectral Analysis of Cardiovascular Variability Signals. Cardiovascular autonomic function was assessed by means of short-term power spectral analysis of HR variability, arterial $\mathrm{BP}$ variability, and spectral estimation of baroreflex sensitivity $(\alpha$-index $)$ at rest and during tilt. Short-term power spectra of HR variability signals were estimated by autoregressive modeling over 250 consecutive beats. According to the HRV guidelines [19], the powers of the two main frequency bands of R-R variability were considered: high-frequency (HF) component (ranging between 0.15 and $0.40 \mathrm{~Hz}$, indirectly reflecting efferent vagal activity and synchronized with the respiratory frequency) and low-frequency (LF) component (ranging between 0.04 and $0.15 \mathrm{~Hz}$ which reflects sympathetic and parasympathetic control and always increases during sympathetic activation) [24]. LF and HF powers were computed in absolute units $\left(\mathrm{ms}^{2}\right)$ and transformed into normalized units (n.u.) (i.e., the percentage of the total spectral power minus the very-low-frequency component) in order to minimize the influence of changes in total power on the LF and HF power values. We also computed the LF to $\mathrm{HF}$ ratio (LF/HF), which is considered to be an index of sympathovagal balance.

2.3.7. Baroreflex Sensitivity Estimation ( $\alpha$-Index). Baroreflex sensitivity ( $\alpha$-index) [25] was computed as the ratio between the spectral power of tachogram and systogram, in the HF $\left(\alpha_{\mathrm{HF}}\right)$ and LF $\left(\alpha_{\mathrm{LF}}\right)$ bands, respectively, and then summed $\left(\alpha_{\mathrm{LF}+\mathrm{HF}}\right), \alpha$-index was expressed as $\mathrm{ms} / \mathrm{mmHg}$.

Results were compared with those obtained in a group of 23 age- and sex-matched healthy subjects who underwent the same HUT-test protocol.
TABLE 2: Valsalva maneuver in JHS/EDS-HT patients who performed the test (\#22).

\begin{tabular}{lc}
\hline Variable & $\mathrm{mmHg} \pm \mathrm{DS}$ \\
\hline Baseline SBP/DBP & $116.7 / 73.9 \pm 15.3 / 11.2$ \\
Maximal drop of SBP during early phase II & $23.5 \pm 9.96$ \\
Maximal drop of DBP during early phase II & $4.8 \pm 4.8$ \\
SBP at late phase II & $125.9 \pm 17.3$ \\
DBP at late phase II & $85.4 \pm 12.2$ \\
SBP at late phase IV & $137.6 \pm 21.2$ \\
DBP at late phase IV & $84.0 \pm 14.8$ \\
Difference between late phase II SBP and & $32.7 \pm 15.6$ \\
early phase II SBP & \\
Difference between late phase II DBP and & $17.6 \pm 6.8$ \\
early phase II DBP & \\
\hline
\end{tabular}

Normal values: Maximal drop of mean blood pressure (MBP) during early phase II: $\geq 20 \mathrm{mmHg}$; systolic blood pressure (SBP) and diastolic blood pressure (DBP) at late phase II: $\geq$ baseline; SBP and DBP at late phase IV: $\geq$ baseline.

2.4. Statistical Analysis. Student's paired $t$-test was used to compare differences in the spectral variables investigated between rest and tilt. Student's unpaired $t$-test was used to compare differences in the spectral variables between groups. A $P$ value of $<0.01$ was considered to indicate statistical significance.

\section{Results}

Thirty-five patients ( 6 men and 29 women, mean age of $35 \pm$ 14 years) with JHS/EDS-HT were included.

3.1. Cardiovascular Reflex Tests. A summary of the cardiovascular reflex tests results was reported in Table 1.

Deep breathing test and 30/15 ratio gave normal results in all patients. Valsalva ratio was also normal in all patients who finished the test $(54.3 \%)$, while $31.4 \%$ patients were not able to conclude the test due to breathing difficulties and incoordination. All patients failed to complete the sustained handgrip test, because pain and fatigue occurred in the early stage of the text $(<1 \mathrm{~min})$, and this did not allow the collection of valid BP values.

Among the 22 patients that completed the Valsalva maneuver, the increase of BP between early phase II and late phase II and the overshoot in late phase IV were observed (Table 2). 
TABLE 3: Valsalva maneuver: comparison of JHS/EDS-HT patients stratified according to the heart rate response to tilting (\#21).

\begin{tabular}{|c|c|c|c|c|}
\hline \multicolumn{2}{|c|}{ POTS (10/35) } & \multicolumn{2}{|c|}{ Non-POTS (11/35) } & \multirow{2}{*}{$P$} \\
\hline Variable & $\mathrm{mmHg} \pm \mathrm{ds}$ & Variable & $\mathrm{mmHg} \pm \mathrm{ds}$ & \\
\hline Baseline SBP/DBP & $117 / 74.5 \pm 11.6 / 6.8$ & Baseline SBP/DBP & $111 / 70 \pm 9.2 / 8$ & $P=0.23$ \\
\hline $\begin{array}{l}\text { Maximal drop of SBP during } \\
\text { early phase II }\end{array}$ & $24.5 \pm 10.6$ & $\begin{array}{l}\text { Maximal drop of SBP during } \\
\text { early phase II }\end{array}$ & $21.9 \pm 24.3$ & $P=0.7$ \\
\hline $\begin{array}{l}\text { maximal drop of DBP during } \\
\text { early phase II }\end{array}$ & $3.9 \pm 9.1$ & $\begin{array}{c}\text { Maximal drop of DBP during } \\
\text { early phase II }\end{array}$ & $3.6 \pm 16$ & $P=0.7$ \\
\hline SBP at late phase II & $125 \pm 13.1$ & SBP at late phase II & $118 \pm 18$ & $P=0.48$ \\
\hline $\mathrm{DBP}$ at late phase II & $89.5 \pm 11.6$ & DBP at late phase II & $84 \pm 17$ & $P=0.4$ \\
\hline SBP at late phase IV & $142.5 \pm 19.6$ & SBP at late phase IV & $132 \pm 22.4$ & $P=0.27$ \\
\hline DBP at late phase IV & $87 \pm 15.6$ & DBP at late phase IV & $78.6 \pm 15.1$ & $P=0.22$ \\
\hline $\begin{array}{l}\text { Difference between late phase II } \\
\text { SBP and early phase II SBP }\end{array}$ & $31.8 \pm 17.9$ & $\begin{array}{l}\text { Difference between late phase II } \\
\text { SBP and early phase II SBP }\end{array}$ & $30.8 \pm 9.2$ & $P=0.6$ \\
\hline $\begin{array}{l}\text { Difference between late phase II } \\
\text { DBP and early phase II DBP }\end{array}$ & $18.9 \pm 9$ & $\begin{array}{l}\text { Difference between late phase II } \\
\text { DBP and early phase II DBP }\end{array}$ & $18.8 \pm 6.3$ & $P=0.7$ \\
\hline
\end{tabular}
(DBP) at late phase II: $\geq$ baseline; SBP and DBP at late phase IV: $\geq$ baseline.

By comparing the Valsalva maneuver between JHS/EDSHT patients with POTS (see below) and those without the criteria for POTS and $\mathrm{OH}$ (see below), no significant differences were observed (Table 3 ).

3.2. HUT-Test and Spectral Analysis. The $\mathrm{HR}$ and BP responses after HUT are showed in Table 4.

Postural tachycardia was common in JHS/EDS-HT. Seventeen $(48.6 \%)$ met the criteria of POTS, 11 (31.4\%) had OI, while 7 (20\%) gave normal results. Only one $(3 \%)$ had $\mathrm{OH}$ while a normal pressure response was observed in the other $34(97 \%)$.

Results of spectral analysis were summarized in Table 5. Analysis of $\mathrm{HR}$ showed comparable results between JHS/EDS-HT and controls. At rest, JHS/EDS-HT patients showed significant higher BRS values compared to controls, while these values became not statistically significant at tilt. BRS values at rest showed further differences by separating the patients' sample in two subgroups (i.e., POTS and non-POTS patients). In particular, we observed a significant higher BRS in the JHS/EDS-HT group with POTS versus controls $(\alpha \mathrm{LF}+\mathrm{HF}=68.4 \pm 41.3 \mathrm{~ms} / \mathrm{mmHg}$ in POTS versus $35.5 \pm 11.0 \mathrm{~ms} / \mathrm{mmHg}$ in controls, $P<0.005$ ), while nonPOTS patients showed a slight but not statistically significant increase of the BRS compared to controls $(\alpha \mathrm{LF}+\mathrm{HF}=49.2$ $\pm 29.6 \mathrm{~ms} / \mathrm{mmHg}$ versus $35.5 \pm 11.0 \mathrm{~ms} / \mathrm{mmHg}$ in controls).

\section{Discussion}

This work confirmed a common perturbation of autonomic regulation of the cardiovascular function in adults with JHS/EDS-HT. POTS and OI were the more commonly observed profiles at HUT, while $\mathrm{OH}$, as a genuine form of autonomic failure, was rare in our sample. Interestingly, we observed a difficulty in completing both the handgrip test and the Valsalva maneuver among the JHS/EDS-HT patients. It is possible that the hand problems related to fatigue and joint pain or instability (so commonly observed in JHS/EDS-HT [26]), as well as the lack of proprioception [27], might have contributed to this pathological outcome. During the Valsalva maneuver, we registered an increase of BP between early phase II and late phase II, and the overshoot in late phase IV in JHS/EDS-HT, as expected in physiological peripheral sympathetic vasoconstriction. The recent finding of small fiber neuropathy as a common finding in EDS, also comprising JHS/EDS-HT, is an intriguing conundrum in light of our findings [28]. In fact, the presence of small fiber neuropathy could identify a clinical subgroup of POTS (a.k.a. "neuropathic" POTS) [29]. In this category of POTS the phase IV overshoot of the Valsalva maneuver is lower than controls, a finding that we were not able to replicate in our sample. This implies a much complex pathogenesis for dysautonomic symptoms in this disorder.

Considering the results obtained with the HUT-test, we found POTS in $\sim 50 \%$ JHS/EDS-HT patients and a high rate of OI in accordance with previous studies [10]. POTS and OI have been frequently described in chronic fatigue syndrome and fibromyalgia, a fact that suggests that these conditions may share deconditioning. Deconditioning could then operate in concert with "somatic hypervigilance" to lead to a disturbing mismatch between physiological responses and perception in some individuals [30]. This could then lead to a vicious cycle of less activity and more deconditioning often worsened by excessive "medicalization." Accordingly, it seems reasonable that exercise-based rehabilitation may be effective in the medium- and long-term treatment of POTS and related conditions with deconditioning [30]. In fact, it has been demonstrated that, during acute exercise, POTS patients have excessive increases in BP and reduced stroke volume at absolute workload compared to sedentary controls without intrinsic abnormality of HR regulation. In addition, cardiac remodeling and blood volume expansion associated with exercise training increase physical fitness and improve performance in these patients [31] 
TABLE 4: Heart rate and blood pressure responses after head-up tilt test.

\begin{tabular}{|c|c|c|c|c|c|c|}
\hline & $\begin{array}{l}\text { HR response } \\
\text { ratio }(\%)\end{array}$ & $\begin{array}{l}\text { HR mean } \\
\text { difference } \\
(\mathrm{bpm} \pm \mathrm{SD})\end{array}$ & & $\begin{array}{l}\text { BP response } \\
\text { ratio }(\%)\end{array}$ & $\begin{array}{c}\text { SBP mean } \\
\text { difference } \\
(\mathrm{mmHg} \pm \mathrm{DS})\end{array}$ & $\begin{array}{l}\text { DBP mean difference } \\
\quad(\mathrm{mmHg} \pm \mathrm{DS})\end{array}$ \\
\hline $\begin{array}{l}\text { Normal } \\
\text { (HR increase between } \\
10 \text { and } 19 \mathrm{bpm} \text { ) }\end{array}$ & $7 / 35(20)$ & $12.5 \pm 2.3$ & Normal & $34 / 35$ (97) & $5.9 \pm 5.8$ & $6.5 \pm 5.8$ \\
\hline $\begin{array}{l}\text { POTS } \\
(\text { HR increase }> \\
30 \mathrm{bpm})\end{array}$ & $17 / 35(48.6)$ & $32 \pm 6.5$ & Orthostatic & & & \\
\hline $\begin{array}{l}\text { Reduced orthostatism } \\
\text { tolerance } \\
\text { (HR increase from } 20 \\
\text { to } 29 \mathrm{bpm} \text { ) }\end{array}$ & $11 / 35(31.4)$ & $20.4 \pm 1.4$ & $\begin{array}{l}\text { hypotension } \\
\text { (reduced peripheral } \\
\text { vessel response) }\end{array}$ & $1 / 35(3)$ & -25 & -15 \\
\hline
\end{tabular}

HR: heart rate. BP: blood pressure. DBP: diastolic blood pressure. SBP: systolic blood pressure.

TABLE 5: Spectral parameters of heart rate variability and baroreflex sensitivity estimation.

\begin{tabular}{|c|c|c|c|c|c|c|}
\hline & \multicolumn{3}{|c|}{ JHS/EDS-HT $(N=35)$} & \multicolumn{3}{|c|}{ Controls $(N=23)$} \\
\hline & Rest & TILT & $\begin{array}{c}P \\
\text { (rest versus tilt) }\end{array}$ & Rest & TILT & $\begin{array}{c}P \\
\text { (rest versus tilt) }\end{array}$ \\
\hline Mean RR [s] & $0.91 \pm 0.14$ & $0.73 \pm 0.12$ & $<0.001$ & $0.89 \pm 0.10$ & $0.76 \pm 0.1$ & $<0.001$ \\
\hline Tot power $\left[\mathrm{msec}^{2}\right]$ & $3281 \pm 2875$ & $2187 \pm 1423$ & n.s & $2419 \pm 1430$ & $1961 \pm 957$ & n.s \\
\hline LF power (u.n.) & $57.0 \pm 21.7$ & $82.7 \pm 10.9$ & $<0.001$ & $57.5 \pm 18.4$ & $82.3 \pm 14.6$ & $<0.001$ \\
\hline HF power (u.n.) & $43.0 \pm 21.7$ & $17.3 \pm 10.9$ & $<0.001$ & $42.5 \pm 18.4$ & $17.7 \pm 14.6$ & $<0.001$ \\
\hline $\mathrm{LF} / \mathrm{HF}$ & $2.18 \pm 1.99$ & $8.36 \pm 8.75$ & $<0.001$ & $1.98 \pm 1.96$ & $12.0 \pm 13.0$ & $<0.002$ \\
\hline$\alpha_{(\mathrm{LF}+\mathrm{HF})}[\mathrm{msec} / \mathrm{mmHg}]$ & $59.1 \pm 36.9^{++}$ & $22.0 \pm 9.6$ & $<0.001$ & $35.5 \pm 11.0$ & $18.5 \pm 8.6$ & $<0.001$ \\
\hline$\alpha_{\mathrm{LF}}[\mathrm{msec} / \mathrm{mmHg}]$ & $21.6 \pm 11.8^{+}$ & $11.5 \pm 5.8$ & $<0.001$ & $15.9 \pm 5.8$ & $10.8 \pm 4.3$ & $<0.001$ \\
\hline$\alpha_{\mathrm{HF}}[\mathrm{msec} / \mathrm{mmHg}]$ & $37.5 \pm 29.4^{++}$ & $10.4 \pm 5.2$ & $<0.001$ & $19.7 \pm 7.8$ & $7.7 \pm 4.9$ & $<0.005$ \\
\hline
\end{tabular}

LF: low frequency

HF: high frequency

$\alpha$ : baroreflex sensitivity

${ }^{+} P<0.02$ JHS/EDS-HT versus controls; ${ }^{++} P<0.001$ JHS/EDS-HT versus controls.

Assessment of autonomic nervous system activity by power spectral analysis of HRV and BPV has attracted growing interest and is already consolidated over the years. Spectral analysis is a noninvasive tool for evaluating the neural mechanisms controlling HR and BP [19]. It identifies the harmonic components of a signal and shows how its power is distributed as a function of frequency. Spectral analysis of HR did not show significant differences in the response to the tilt maneuver between JHS/EDS-HT and controls. In response to orthostatic stimulation, we observed comparable changes in the HR markers of sympathetic activation and parasympathetic withdrawal in both groups. An interesting finding of our study is that the BRS of JHS/EDS-HT patients, at rest, is significantly higher than controls and this difference is more marked in the subgroup of patients with POTS. Different hypothesis can explain the BRS variations. The resting HR seems to be influenced by exercise. Different studies have demonstrated reduction of intrinsic HR induced by long-term competitive training in athletes compared with sedentary individuals $[32,33]$. Another possible mechanism to explain the abnormalities of BRS in JHS/EDS-HT may be linked to the reduction of artery stiffness in the elderly [34]. Since the deformation of the baroreceptors rather than direct intravessel pressure during acute changes in arterial pressure is required to initiate neural firing, stiffness of the large elastic arteries with baroreceptors (i.e., carotid artery, the aortic arch) could be associated with a decrease in BRS [34]. From this perspective, it should be possible to speculate that the modification of the connective tissue which characterizes JHS/EDS-HT may modify vessels compliance and should explain the differences observed in the baroreflex function.

4.1. Limitations. This study have some limitations: firstly autonomic cardiovascular symptoms are not tested using specific questionnaire (e.g., the Composite Autonomic Scoring Scale) and no correlation between clinical and instrumental results is present; the number of patients is reduced; symptoms and tests have not been reevaluated during the natural history of the JHS/EDS-HT in order to analyze possible variations or the response to clinical and pharmacological therapies. Future studies are needed in order to study the changes of autonomic regulation before and after therapeutic exercise or after low intensity sports activities and they might be also introduced in future research with the aim of identifying more reliable markers for the effects rehabilitation in such a complex disorder. Symptoms should be observed 
in a longer period following the different phases of the syndrome; moreover it should be useful to better investigate the vascular stiffness in JHS/EDS-HT patients and its possible role in the genesis of the results founded.

$\begin{array}{ll}\text { Abbreviations } \\ \text { BP: } & \text { Blood pressure } \\ \text { bpm: } & \text { Beats per minute } \\ \text { BRS: } & \text { Baroreflex sensitivity } \\ \text { DBP: } & \text { Diastolic blood pressure } \\ \text { ECG: } & \text { Electrocardiogram } \\ \text { EDS: } & \text { Ehlers-Danlos syndrome } \\ \text { EDS-HT: } & \text { Ehlers-Danlos syndrome, hypermobility type } \\ \text { HF: } & \text { High-frequency } \\ \text { HR: } & \text { Heart rate } \\ \text { HRV: } & \text { Heart rate variability } \\ \text { HUT: } & \text { Head-up tilt } \\ \text { JHS: } & \text { Joint hypermobility syndrome } \\ \text { LF: } & \text { Low-frequency } \\ \text { LF/HF: } & \text { Low-frequency/high-frequency ratio } \\ \text { n.u.: } & \text { Normalized units } \\ \text { OH: } & \text { Orthostatic hypotension } \\ \text { OI: } & \text { Orthostatic intolerance } \\ \text { POTS: } & \text { Postural orthostatic tachycardia syndrome } \\ \text { SBP: } & \text { Systolic blood pressure } \\ \text { VR: } & \text { Valsalva ratio. }\end{array}$

\section{Competing Interests}

The authors declare that there is no conflict of interests regarding the publication of this paper.

\section{References}

[1] P. Beighton, A. De Paepe, B. Steinmann, P. Tsipouras, and R. J. Wenstrup, "Ehlers-Danlos syndromes: revised nosology, Villefranche, 1997. Ehlers-Danlos National Foundation (USA) and Ehlers-Danlos Support Group (UK)," American Journal of Medical Genetics, vol. 77, no. 1, pp. 31-37, 1998.

[2] B. T. Tinkle, H. A. Bird, R. Grahame, M. Lavallee, H. P. Levy, and D. Sillence, "The lack of clinical distinction between the hypermobility type of Ehlers-Danlos syndrome and the joint hypermobility syndrome (a.k.a. hypermobility syndrome)," American Journal of Medical Genetics Part A, vol. 149, no. 11, pp. 2368-2370, 2009.

[3] M. Castori, C. Dordoni, S. Morlino et al., "Spectrum of mucocutaneous manifestations in 277 patients with joint hypermobility syndrome/Ehlers-Danlos syndrome, hypermobility type," American Journal of Medical Genetics, Part C: Seminars in Medical Genetics, vol. 169, no. 1, pp. 43-53, 2015.

[4] R. Grahame, H. A. Bird, A. Child et al., "The revised (Brighton 1998) criteria for the diagnosis of benign joint hypermobility syndrome (BJHS)," Journal of Rheumatology, vol. 27, no. 7, pp. 1777-1779, 2000.

[5] A. De Paepe and F. Malfait, "The Ehlers-Danlos syndrome, a disorder with many faces," Clinical Genetics, vol. 82, no. 1, pp. 1-11, 2012.

[6] M. Castori, I. Sperduti, C. Celletti, F. Camerota, and P. Grammatico, "Symptom and joint mobility progression in the joint hypermobility syndrome (Ehlers-Danlos syndrome, hypermobility type)," Clinical and Experimental Rheumatology, vol. 29, no. 6, pp. 998-1005, 2011.

[7] L. Rombaut, A. De Paepe, F. Malfait, A. Cools, and P. Calders, "Joint position sense and vibratory perception sense in patients with Ehlers-Danlos syndrome type III (hypermobility type)," Clinical Rheumatology, vol. 29, no. 3, pp. 289-295, 2010.

[8] I. De Wandele, L. Rombaut, L. Leybaert et al., "Dysautonomia and its underlying mechanisms in the hypermobility type of Ehlers-Danlos syndrome," Seminars in Arthritis and Rheumatism, vol. 44, no. 1, pp. 93-100, 2014.

[9] Y. Gazit, A. M. Nahir, R. Grahame, and G. Jacob, "Dysautonomia in the joint hypermobility syndrome," American Journal of Medicine, vol. 115, no. 1, pp. 33-40, 2003.

[10] I. De Wandele, L. Rombaut, T. De Backer et al., "Orthostatic intolerance and fatigue in the hypermobility type of EhlersDanlos Syndrome," Rheumatology, vol. 55, no. 8, pp. 1412-1420, 2016.

[11] E. M. Garland, J. E. Celedonio, and S. R. Raj, "Postural tachycardia syndrome: beyond orthostatic intolerance," Current Neurology and Neuroscience Reports, vol. 15, article 60, 2015.

[12] E. Grigoriou, J. R. Boris, and J. P. Dormans, "Postural orthostatic tachycardia syndrome (POTS): association with EhlersDanlos syndrome and orthopaedic considerations," Clinical Orthopaedics and Related Research, vol. 473, no. 2, pp. 722-728, 2015.

[13] D. Wallman, J. Weinberg, and A. D. Hohler, "Ehlers-Danlos syndrome and postural tachycardia syndrome: a relationship study," Journal of the Neurological Sciences, vol. 340, no. 1-2, pp. 99-102, 2014.

[14] S. Carew, M. O. Connor, J. Cooke et al., "A review of postural orthostatic tachycardia syndrome," Europace, vol. 11, no. 1, pp. 18-25, 2009.

[15] E. M. Garland, J. E. Celedonio, and S. R. Raj, "Postural tachycardia syndrome: beyond orthostatic intolerance," Current Neurology and Neuroscience Reports, vol. 15, no. 9, article 60, 2015.

[16] E. E. Benarroch, "Postural tachycardia syndrome: a heterogeneous and multifactorial disorder," Mayo Clinic Proceedings, vol. 87, no. 12, pp. 1214-1225, 2012.

[17] P. Beighton, L. Solomon, and C. L. Soskolne, "Articular mobility in an African population," Annals of the Rheumatic Diseases, vol. 32, no. 5, pp. 413-418, 1973.

[18] M. Castori, C. Dordoni, M. Valiante et al., "Nosology and inheritance pattern(s) of joint hypermobility syndrome and EhlersDanlos syndrome, hypermobility type: a study of intrafamilial and interfamilial variability in 23 Italian pedigrees," American Journal of Medical Genetics A, vol. 164, no. 12, pp. 3010-3020, 2014.

[19] Task Force of the European Society of Cardiology and North American Society of Pacing and Electrophysiology, "Heart rate variability. Standards of measurement, physiological interpretation and clinical use," Circulation, vol. 93, no. 5, pp. 1043-1065, 1996.

[20] J. Ewing David, "Recent advances in the non invasive investigation of diabetic autonomic neuropathy," in Autonomic Failure. A Textbook of Clinical Disorders of the Autonomic Nervous System, S. R. Bannister, Ed., pp. 667-689, Oxford University Press, 2nd edition, 1988.

[21] P. Novak, "Quantitative autonomic testing," Journal of Visualized Experiments, no. 53, Article ID e2502, 2011. 
[22] R. Freeman, W. Wieling, F. B. Axelrod et al., "Consensus statement on the definition of orthostatic hypotension, neurally mediated syncope and the postural tachycardia syndrome," Autonomic Neuroscience: Basic and Clinical, vol. 161, no. 1-2, pp. 46-48, 2011.

[23] R. S. Sheldon, B. P. Grubb, B. Olshansky et al., "2015 heart rhythm society expert consensus statement on the diagnosis and treatment of postural tachycardia syndrome, inappropriate sinus tachycardia, and vasovagal syncope," Heart Rhythm, vol. 12, no. 6, pp. e41-e63, 2015.

[24] G. Baselli, S. Cerutti, S. Civardi et al., "Spectral and crossspectral analysis of heart rate and arterial blood pressure variability signals," Computers and Biomedical Research, vol. 19, no. 6, pp. 520-534, 1986.

[25] M. Pagani, N. Montano, A. Porta et al., "Relationship between spectral components of cardiovascular variabilities and direct measures of muscle sympathetic nerve activity in humans," Circulation, vol. 95, no. 6, pp. 1441-1448, 1997.

[26] J. M. Wolf, K. L. Cameron, and B. D. Owens, "Impact of joint laxity and hypermobility on the musculoskeletal system," The Journal of the American Academy of Orthopaedic Surgeons, vol. 19, no. 8, pp. 463-471, 2011.

[27] T. O. Smith, E. Jerman, V. Easton et al., "Do people with benign joint hypermobility syndrome (BJHS) have reduced joint proprioception? A systematic review and meta-analysis," Rheumatology International, vol. 33, no. 11, pp. 2709-2716, 2013.

[28] D. Cazzato, M. Castori, R. Lombardi et al., "Small fiber neuropathy is a common feature of Ehlers-Danlos syndromes," Neurology, vol. 87, no. 2, pp. 155-159, 2016.

[29] C. H. Gibbons, I. Bonyhay, A. Benson, N. Wang, and R. Freeman, "Structural and functional small fiber abnormalities in the neuropathic postural tachycardia syndrome," PLoS ONE, vol. 8, no. 12, Article ID e84716, 2013.

[30] M. J. Joyner and S. Masuki, "POTS versus deconditioning: the same or different?" Clinical Autonomic Research, vol. 18, no. 6, pp. 300-307, 2008.

[31] Q. Fu and B. D. Levine, "Exercise in the postural orthostatic tachycardia syndrome," Autonomic Neuroscience: Basic and Clinical, vol. 188, pp. 86-89, 2015.

[32] P. G. Katona, M. McLean, D. H. Dighton, and A. Guz, "Sympathetic and parasympathetic cardiac control in athletes and nonathletes at rest," Journal of Applied Physiology Respiratory Environmental and Exercise Physiology, vol. 52, no. 6, pp. 1652$1657,1982$.

[33] S. Strano, S. Lino, G. Calcagnini et al., "Respiratory sinus arrhythmia and cardiovascular neural regulation in athletes," Medicine and Science in Sports and Exercise, vol. 30, no. 2, pp. 215-219, 1998.

[34] Y. Okada, M. M. Galbreath, S. Shibata et al., "Relationship between sympathetic baroreflex sensitivity and arterial stiffness in elderly men and women," Hypertension, vol. 59, no. 1, pp. 98104, 2012. 


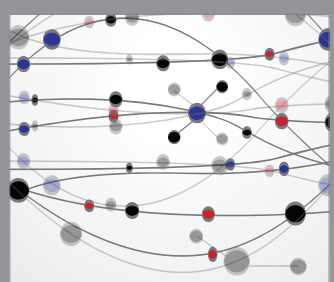

The Scientific World Journal
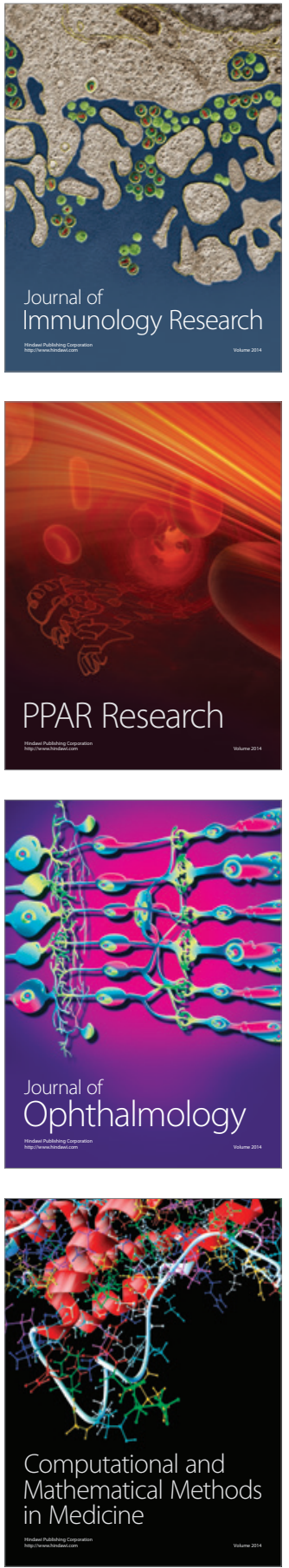

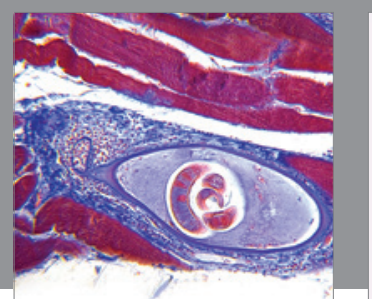

Gastroenterology Research and Practice
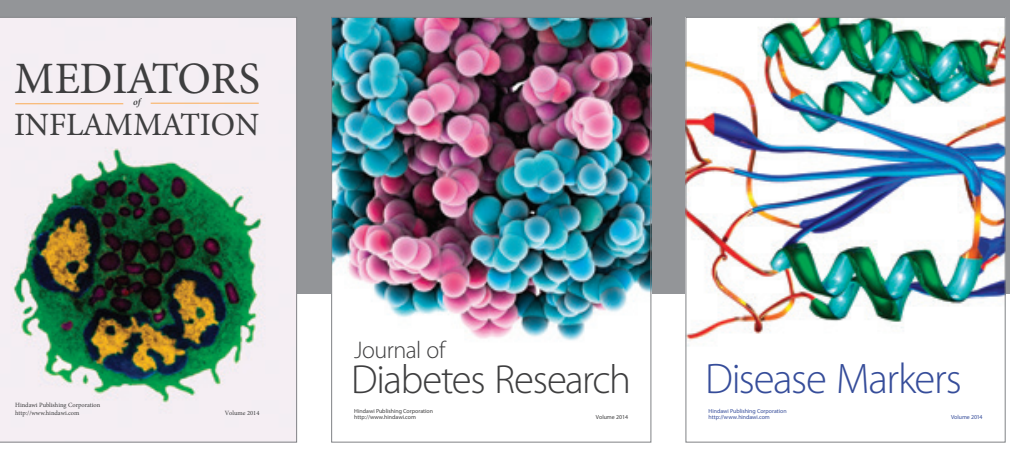

Disease Markers

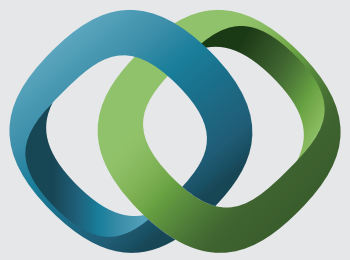

\section{Hindawi}

Submit your manuscripts at

https://www.hindawi.com
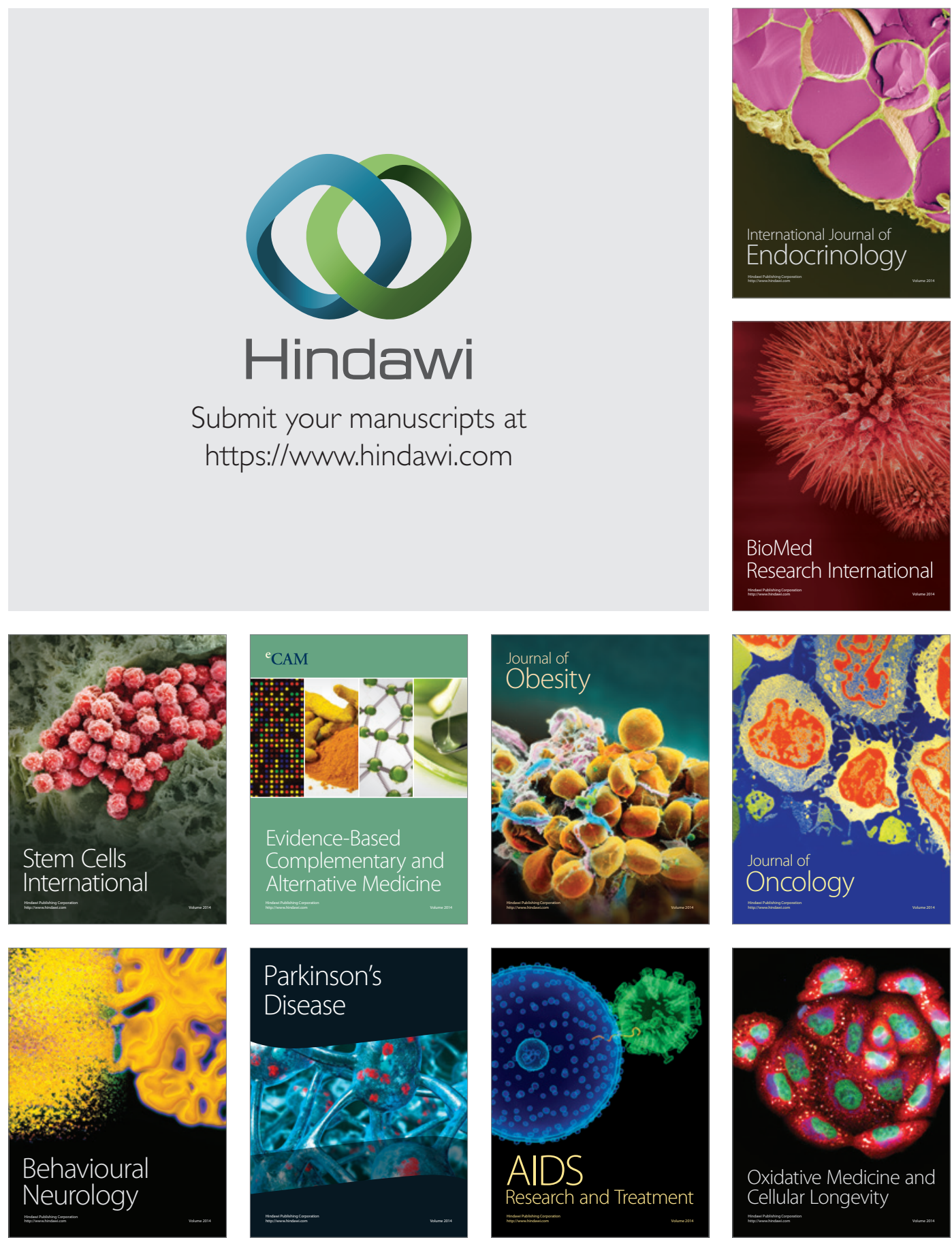